\title{
Hemodynamic variables and progression of acute kidney injury in critically ill patients with severe sepsis: data from the prospective observational FINNAKI study
}

Meri Poukkanen ${ }^{1 \dagger}$, Erika Wilkmann ${ }^{2 *}$, Suvi T Vaara ${ }^{2}$, Ville Pettilä ${ }^{2,3}$, Kirsi-Maija Kaukonen ${ }^{4}$, Anna-Maija Korhonen ${ }^{2}$, Ari Uusaro ${ }^{5}$, Seppo Hovilehto ${ }^{6}$, Outi Inkinen ${ }^{7}$, Raili Laru-Sompa ${ }^{8}$, Raku Hautamäki ${ }^{9}$, Anne Kuitunen ${ }^{10}$,

Sari Karlsson ${ }^{10}$ and the FINNAKI Study Group

\begin{abstract}
Introduction: Knowledge of the association of hemodynamics with progression of septic acute kidney injury (AKI) is limited. However, some recent data suggest that mean arterial pressure (MAP) exceeding current guidelines (60-65 mmHg) may be needed to prevent AKI. We hypothesized that higher MAP during the first 24 hours in the intensive care unit (ICU), would be associated with a lower risk of progression of AKI in patients with severe sepsis.

Methods: We identified 423 patients with severe sepsis and electronically recorded continuous hemodynamic data in the prospective observational FINNAKI study. The primary endpoint was progression of AKI within the first 5 days of ICU admission defined as new onset or worsening of AKI by the Kidney Disease: Improving Global Outcomes (KDIGO) criteria. We evaluated the association of hemodynamic variables with this endpoint. We included 53724 10-minute medians of MAP in the analysis. We analysed the ability of time-adjusted MAP to predict progression of AKI by receiver operating characteristic (ROC) analysis.

Results: Of 423 patients, 153 (36.2\%) had progression of AKI. Patients with progression of AKI had significantly lower time-adjusted MAP, $74.4 \mathrm{mmHg}$ [68.3-80.8], than those without progression, $78.6 \mathrm{mmHg}$ [72.9-85.4], $P<0.001$. A cut-off value of $73 \mathrm{mmHg}$ for time-adjusted MAP best predicted the progression of AKl. Chronic kidney disease, higher lactate, higher dose of furosemide, use of dobutamine and time-adjusted MAP below $73 \mathrm{mmHg}$ were independent predictors of progression of AKI.
\end{abstract}

Conclusions: The findings of this large prospective multicenter observational study suggest that hypotensive episodes (MAP under $73 \mathrm{mmHg}$ ) are associated with progression of AKI in critically ill patients with severe sepsis.

\section{Introduction}

Both the incidence of severe sepsis and acute kidney injury (AKI) are increasing [1-3]. The incidence of AKI among patients with severe sepsis is 40 to $50 \%$ and sepsis accounts for half of the cases of AKI in the intensive care unit (ICU) [1,4-7]. Patients with septic AKI have worse outcome than septic patients without

\footnotetext{
* Correspondence: erika.wilkman@hus.fi

${ }^{\dagger}$ Equal contributors

${ }^{2}$ Intensive Care Unit, Division of Anaesthesia and Intensive Care Medicine, Department of Surgery, Helsinki, Finland

Full list of author information is available at the end of the article
}

AKI in terms of longer ICU and hospital stays and higher mortality [6,7].

The understanding of the underlying pathophysiology of septic AKI is still limited [5,8]. Previously, the reduction in renal blood flow has been proposed to be essential for the establishment of AKI [9]. However, this explanation alone is inadequate. The pathogenesis of septic AKI is complex, involving apoptosis [10], inflammatory responses, and changes in microcirculation $[5,8,11]$. The blood flow to the organs is pressure-dependent outside the values of the autoregulatory threshold. However, a recent study reported that the autoregulation of renal

\section{() BioMed Central}


blood flow is deranged in critical illness prior to and during AKI, and varies with cardiac output [12].

Current guidelines suggest norepinephrine and fluid therapy to maintain mean arterial pressure (MAP) $\geq 60$ $65 \mathrm{mmHg}$ for sufficient renal perfusion and prevention of AKI in critically ill patients $[11,13]$. However, limited knowledge exists of the association of hemodynamics, MAP in particular, with progression of AKI during the early phase of severe sepsis $[14,15]$. As other options for treatment or prevention of AKI are scarce [13], better knowledge of the association of hemodynamic factors is essential. We hypothesized that higher MAP would be independently associated with a lower risk of progression of AKI.

Accordingly, in this predefined substudy of the prospective, multicenter FINNAKI study [16], we scrutinized the associations of hemodynamic variables, especially MAP, with progression of AKI in patients with severe sepsis.

\section{Materials and methods}

The ethics committee of the Helsinki University Hospital gave approval for the study and for a deferred consent policy. Written, informed consent was obtained from the patient or patient's proxy.

\section{Patients}

We identified all patients with severe sepsis and electronically recorded continuous hemodynamic data from the prospective observational FINNAKI study that was conducted in 17 Finnish ICUs between 1 September 2011 and 1 February 2012 [16]. First, we excluded four ICUs, in which median values of hemodynamic parameters were registered for periods of more than 10 minutes, or the data on vasoactive treatment were incomplete. Second, we excluded patients with severe sepsis diagnosed later than $24 \mathrm{~h}$ after ICU admission. Third, we excluded patients who died during the first five days in the ICU (Additional file 1 presents data on these patients) or who reached the primary endpoint within $12 \mathrm{~h}$ after ICU admission. The numbers of study patients and excluded patients are presented in Figure 1.

\section{Definitions}

We defined severe sepsis according to the American College of Chest Physicians/Society of Critical Care Medicine (ACCP/SCCM) Consensus Conference Committee definition [17]. We used the Kidney Disease: Improving Global Outcomes (KDIGO) criteria to define and stage AKI according to changes in serum creatinine $(\mathrm{SCr})$ and urine output [18]. According to KDIGO criteria, AKI is defined by an increase in SCr by $\geq 26.5 \mu \mathrm{mol} / \mathrm{l}$ within $48 \mathrm{~h}$, or an increase in $\mathrm{SCr} \geq 1.5$ times baseline value, or urine output less than $<0.5 \mathrm{ml}$ per $\mathrm{kg} / \mathrm{h}$ for six hours. We used the last $\mathrm{SCr}$ value from the previous year excluding the week

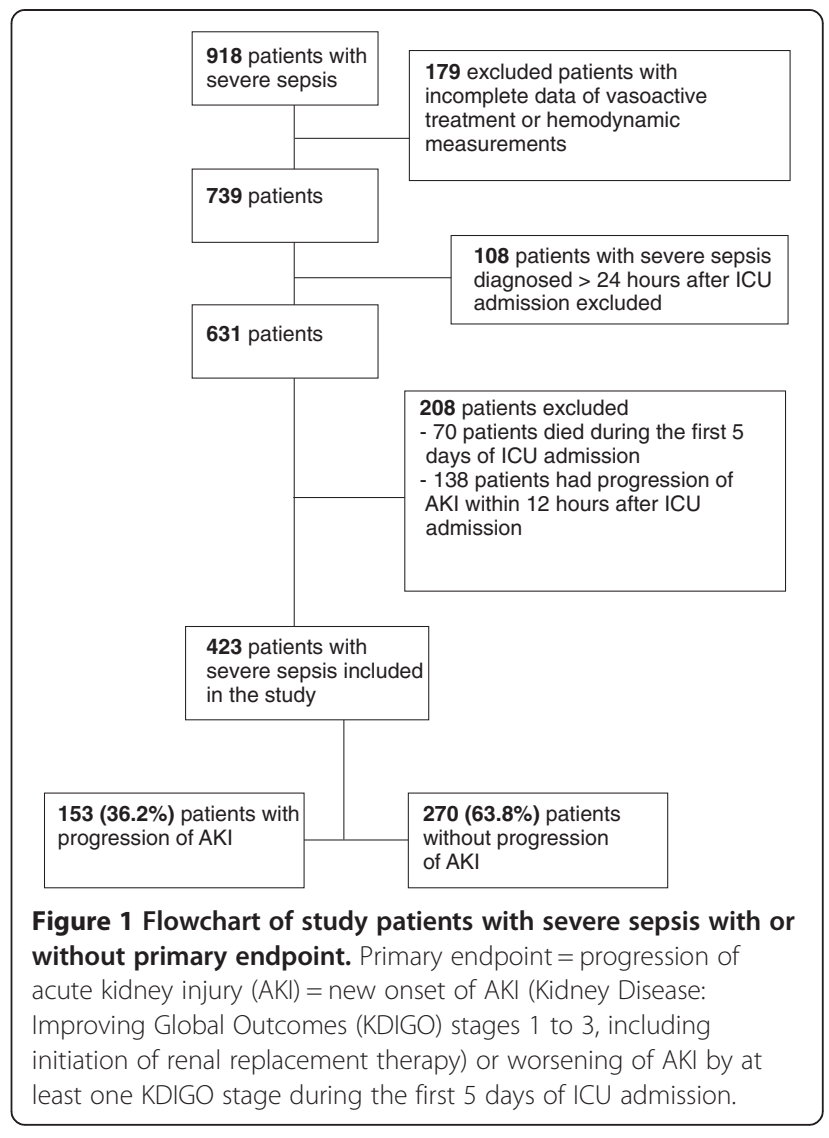

before the ICU admission as baseline SCr, and for those without a baseline value $(\mathrm{n}=292)$ we estimated it using the modification in diet in renal disease (MDRD) equation [19], assuming a glomerular filtration rate (GFR) of $75 \mathrm{ml}$ per minute $/ 1.73 \mathrm{~m}^{2}$. When available, we also used $\mathrm{SCr}$ values within $48 \mathrm{~h}$ before ICU admission to identify the acute increase in SCr. We defined the primary endpoint (progression of AKI) as follows: 1) new onset of AKI (KDIGO stages 1 to 3, including initiation of renal replacement therapy, RRT) or 2) worsening of AKI by at least one KDIGO stage during the first 5 days of ICU admission. The negative primary endpoint was defined as absence of AKI within the first 5 days in the ICU. Chronic kidney disease (CKD) was defined as structural or functional abnormalities of the kidney or GFR $<60 \mathrm{ml}$ per minute $/ 1.73 \mathrm{~m}^{2}$ at least one week prior to ICU admission [20]. Hypotension within $48 \mathrm{~h}$ prior to ICU admission was defined as systolic blood pressure $<90 \mathrm{mmHg}$ for $1 \mathrm{~h}$ and hypovolemia according to the judgement of the physician. The attending physician set the targeted MAP level according to local practice and current sepsis guidelines [21].

\section{Data collection}

We prospectively collected routine data (demographics, diagnosis by International Classification of Diseases (ICD-10), ICU scores, physiologic measures, and outcome) 
to the Finnish Intensive Care Consortium database maintained by Tieto Ltd, Helsinki, Finland [16]. Additionally, we completed a standardized case report form (CRF) at admission, and daily during days one to five in the ICU, and at ICU and hospital discharge. The CRF data comprised data on chronic and present health information, risk factors for $\mathrm{AKI}$, severe sepsis, infections and antimicrobial treatment, organ dysfunction, fluid balance, and information on RRT [16]. The KDIGO stage was calculated continuously for each patient based on every measured creatinine value and hourly urine output [16]. We also prospectively collected data on hemodynamic measurements and vasopressor and inotrope treatment for this substudy.

The MAP data were collected into the database as median values of 2 or 5 minutes depending on the local patient data management system. Before collection to the database all data were manually validated for the first 24 hours of ICU admission to eradicate erroneous values. We converted all MAP data into 10-minute median values (MAP values) for all analyses.

\section{Data analyses}

We first calculated the area under the curve (AUC) for MAP values using the NCSS 8 software (Kaysville, UT, USA) by placing the MAP values (10-minute medians) on the $y$-axis and time of MAP registrations as 10-minute periods on the $\mathrm{x}$-axis (see Additional file 2: Figures S1A, B, and $\mathrm{C}$ ). We adjusted the MAP AUCs with the total aggregate time of MAP registrations (that is, the sum of 10-minute periods of MAP median values) for each patient during the first $24 \mathrm{~h}$ (= time-adjusted MAP). For patients who reached the endpoint within $24 \mathrm{~h}$, MAP registrations were included in the analysis until the endpoint was reached. The point of time of the highest AKI stage was the time of reaching the endpoint. For patients who did not reach the endpoint within $24 \mathrm{~h}$, MAP values of the first $24 \mathrm{~h}$ were included in the analysis.

Second, we calculated the MAP AUC under threshold values of MAP: $55,60,65,70,75,80,85 \mathrm{mmHg}$ as the area of MAP and aggregate time of MAP values beneath each threshold. Third, we calculated the aggregate time and adjusted aggregate time (percentage) of MAP below threshold values $(55,60,65,70,75,80,85 \mathrm{mmHg})$ for each patient. Fourth, we calculated the time-adjusted MAP deficit below threshold values $(55,60,65,70,75$, $80,85 \mathrm{mmHg}$ ) by dividing the MAP AUC below each threshold value with the total aggregate time of MAP values for each patient (Additional file 2: Figures S1A, B, and $\mathrm{C}$ ). Fifth, we identified patients with time-adjusted MAP below the best cutoff value for prediction of AKI progression based on the receiver operating characteristic (ROC) analysis of the time-adjusted MAP. Sixth, the time-adjusted MAP below this level was used as a categorical variable in the multivariable regression analysis.

We identified the highest blood lactate value, the lowest blood $\mathrm{pH}$ value and the lowest base excess (BE) values for each patient for the first $24 \mathrm{~h}$ and during days one to five. The worst values of the first $24 \mathrm{~h}$ were used in the analysis. The highest dose of norepinephrine, epinephrine, dopamine, dobutamine, and vasopressin for the first $24 \mathrm{~h}$ were used in the analyses. We calculated the vasopressor load using the following formula: vasopressor load $(\mu \mathrm{g} / \mathrm{kg} /$ minute $)=$ norepinephrine $(\mu \mathrm{g} / \mathrm{kg} / \mathrm{minute})+$ dopamine $(\mu \mathrm{g} / \mathrm{kg} /$ minute $/ 2)+$ epinephrine $(\mu \mathrm{g} / \mathrm{kg} /$ minute $)+$ phenylephrine $(\mu \mathrm{g} / \mathrm{kg} /$ minute $/ 10)[22,23]$. In the study ICUs, phenylephrine infusions were not used, and thus, it was not included in the vasopressor load. We defined treatment with dobutamine, milrinone or levosimendan as inotrope treatment, epinephrine was analyzed as a vasopressor only [24]. We calculated the time-adjusted fluid balance for the first day in ICU by dividing the total fluid balance by the number of hours in the ICU at fluid balance registration. We defined hydroxyethyl starch (HES) and gelatine as colloids.

\section{Statistical analyses}

We present the data as absolute number (percentage) or median with IQR. For continuous data, we used the Mann-Whitney $U$-test for comparison of groups. For categorical data, we used the chi-square test or Fisher's exact test, when appropriate. We analyzed the association of hemodynamic data and risk factors for progression of AKI with the primary endpoint by univariable analysis. We then included prognostic factors with $P<0.2$ into a multivariable forward conditional regression analysis to test the possible independent association with the primary endpoint. We analyzed the ability of time-adjusted MAP and highest dose of norepinephrine to predict worsening of AKI by calculating the AUC by ROC analysis with the primary endpoint. We assessed the best cutoff value by the Youden Index (sensitivity + specificity -1) [25]. We performed all statistical analyses using IBM SPSS Statistics 19.0 and 20.0 (IBM, Armonk, NY, USA) or NCSS 8 (Kaysville, UT, USA) software.

\section{Results}

\section{Incidence of AKI and progression of AKI}

We included 423 patients with severe sepsis in the study (Figure 1). Of these 423 patients, 153 (36.2\%) had AKI and presented with primary endpoint (progression of AKI) within 5 days of ICU admission. Patients with progression of AKI more often suffered from septic shock $(134 / 153,87.6 \%)$ compared to those without progression (185/270, 68.5\%), $P<0.001$. They also had CKD, diabetes mellitus, suffered from hypovolemia and hypotension prior to ICU admission and had received radiocontrast 
dye preceding ICU admission more often than those without progression of AKI (Table 1). The 90-day mortality of patients with severe sepsis with progression of AKI was higher than for patients with severe sepsis without progression of AKI (32.7\% versus $18.9 \%, P=0.001$ ). The ICU mortality did not differ significantly between the groups $(7.8 \%$ versus $3.3 \%$ respectively, $P=0.06)$.

Of these 423 patients, $102(24.1 \%)$ had new onset of AKI and 51 (12.1\%) had worsening of AKI by at least one KDIGO stage. The highest AKI stage was based on changes in SCr in $80.1 \%$ (339/423), urine output 13.9\% (59/423) and by initiation of RRT in 25 cases (5.9\%). The progression of AKI is illustrated in Additional file 3. The median time for reaching the endpoint was 27.0 hours (16.5 to 45.5 hours). Of 153 patients with progression of AKI, 66 (43.1\%) reached the endpoint on the admission day, and 50 patients $(32.7 \%)$ on the second day in the ICU. RRT was initiated in $34 / 423(8 \%)$ of the study patients.

\section{MAP and progression of AKI}

We included 53,724 10-minute medians of MAP values in the calculations. The median aggregate MAP registration time for patients who fulfilled the endpoint was $1,230$ (945 to 1,430$)$ minutes compared to $1,420(1,350$ to 1,440$)$ minutes in those who did not fulfill the endpoint. Patients with progression of AKI had significantly lower time-adjusted MAP, $74.4 \mathrm{mmHg}$ (68.3 to 80.8), than those without progression, $78.6 \mathrm{mmHg}$ (72.9 to 85.4), $P<0.001$ (Additional file 4). The time-adjusted MAP and aggregate times of MAP values below MAP thresholds of patients with or without progression of AKI are presented in Table 2. Except for threshold level $85 \mathrm{mmHg}(P=0.07)$, the MAP AUC below thresholds (55 to $80 \mathrm{mmHg}$ ) were larger in patients with progression of AKI than without ( $P>0.05$ for all) (Additional file 5 ). The time-adjusted MAP deficits were larger for all threshold levels $(55 \mathrm{mmHg}$ and $85 \mathrm{mmHg}, P<0.05$ for all) (Additional file 5). The Youden index of the time-adjusted MAP yielded a cutoff value of $72.7 \mathrm{mmHg}$ for best prediction of AKI progression, (ROC AUC 0.63; CI 95\% 0.58 to 0.69 ), sensitivity 0.44 ; CI $95 \% 0.36$ to 0.52 ), specificity 0.76 ; CI $95 \% 0.71$ to 0.81 ). The incidence of AKI progression divided by quintiles of time-adjusted MAP is shown in Figure 2.

\section{Vasopressor and inotrope treatment}

Of the 423 patients with severe sepsis, 311 (73.5\%) were treated with norepinephrine within the first 5 days of ICU admission, and 293 (69.3\%) patients received norepinephrine during the first $24 \mathrm{~h}$ in ICU. Patients with progression of AKI received norepinephrine more often $(P<0.001)$ during days 1 to 5 in the ICU. The maximum dose of norepinephrine was higher both during the first $24 \mathrm{~h}(P<0.001)$ and within the first 5 days in the ICU $(P<0.001)$. Patients with progression of AKI also received inotropes more often than patients with no AKI progression, $26.1 \%$ versus $7.4 \%, P<0.001$. Table 2 presents details of vasopressor and inotrope treatment.

Patients with progression of AKI by quintiles of highest norepinephrine dose are presented in Figure 3. When patients were divided into quintiles according to timeadjusted MAP, the highest dose of norepinephrine during $24 \mathrm{~h}$ was significantly associated with AKI progression in the lowest quintile of time-adjusted MAP (47.2 to 69.5 $\mathrm{mmHg})(P<0.001)$, but not in the four higher quintiles $(P=0.33, P=0.92, P=0.16$ and $P=0.78$ respectively). The maximum vasopressor load was higher in patients with progression of AKI than in patients without progression of AKI $(P<0.001)$.

The Youden index of the highest norepinephrine dose yielded a cutoff value of $0.19 \mu \mathrm{g} / \mathrm{kg} /$ minute $\mathrm{mmHg}$ for best prediction of AKI progression (ROC AUC 0.66, CI $95 \% 0.60$ to 0.71 ; sensitivity 0.44 , CI $95 \% 0.37$ to 0.52 ; specificity 0.80 , CI $95 \% 0.75$ to 0.85 ).

Patients with time-adjusted MAP below $73 \mathrm{mmHg}$ and highest dose of norepinephrine over $0.19 \mu \mathrm{g} / \mathrm{kg} /$ minute (42/61 patients, 68.9\%) developed AKI more frequently than patients with time-adjusted MAP over $73 \mathrm{mmHg}$ and norepinephrine below $0.19 \mu \mathrm{g} / \mathrm{kg} /$ minute (58/226 patients, $25.7 \%$ ), odds ratio (OR) $6.40,95 \%$ CI 3.45 to 11.89 .

\section{Other factors associated with progression of AKI}

Of the 423 patients, 68 (16.1\%) received HES and 89 (21.0\%) received gelatine within $48 \mathrm{~h}$ preceding ICU admission. Within the first 5 days of ICU admission patients with progression of AKI received colloids (type not specified) more often than those without $(74.5 \%$ versus $59.3 \%, P=0.002$ ). The fluid balance on admission day was significantly higher in patients with progression of AKI (112.8 ml/h, 7.4 to $216.4 \mathrm{ml} / \mathrm{h})$ than among those without progression, $51.7 \mathrm{ml} / \mathrm{h},-20.5$ to $138.6 \mathrm{ml} / \mathrm{h}$ ), $P<0.001)$. Patients with progression of AKI had higher blood lactate levels, lower blood $\mathrm{pH}$ levels and lower $\mathrm{BE}$ values than patients without progression both during the first $24 \mathrm{~h}$ and during days 1 to $5(P<0.001$ for all $)$ (Additional file 6). Hypertension as co-morbidity prior to ICU admission was not associated with progression of AKI $(P=0.23)$. Time-adjusted MAP was higher in patients with hypertension than in patients without hypertension; $78.5 \mathrm{mmHg}(72.7 \mathrm{mmHg}$ to $84.2 \mathrm{mmHg}$ ) versus 75.6 (70.3 $\mathrm{mmHg}$ to $82.9 \mathrm{mmHg}$ ) respectively, $P=0.04$ ).

\section{Multivariable logistic regression analysis}

Results of the univariable and multivariable regression analyses are shown in Table 3.

No significant interaction between time-adjusted MAP and dose of norepinephrine was detected. 
Table 1 Characteristics of patients with severe sepsis with or without progression of AKI

\begin{tabular}{|c|c|c|c|c|c|}
\hline & \multirow[t]{2}{*}{ Data available } & \multirow{2}{*}{$\frac{\text { Progression of } A K I}{N=153}$} & \multirow[t]{2}{*}{ Data available } & \multirow{2}{*}{$\begin{array}{l}\text { No progression of } A K I \\
N=270\end{array}$} & \multirow[t]{2}{*}{$P$-value } \\
\hline & & & & & \\
\hline Age, years & 153 & $64.0(51.0$ to 78.0$)$ & 270 & $63.0(52.0$ to 73.0$)$ & 0.1 \\
\hline Gender, male & 153 & $92(60.1)$ & 270 & $184(68.1)$ & 0.1 \\
\hline Baseline creatinine available & 153 & $108(70.6)$ & 270 & $184(68.1)$ & 0.6 \\
\hline \multicolumn{6}{|l|}{ Comorbidity } \\
\hline Hypertension & 153 & $81(52.9)$ & 270 & $126(46.7)$ & 0.22 \\
\hline Systolic heart failure or arteriosclerosis & 153 & $30(19.6)$ & 270 & $45(16.7)$ & 0.45 \\
\hline COPD & 153 & $15(9.8)$ & 270 & $38(14.1)$ & 0.2 \\
\hline Chronic kidney disease & 153 & $17(11.1)$ & 270 & $7(2.6)$ & $<0.001$ \\
\hline Chronic liver disease & 153 & $8(5.2)$ & 270 & $12(4.4)$ & 0.72 \\
\hline Diabetes mellitus & 153 & $42(27.5)$ & 270 & $50(18.5)$ & 0.032 \\
\hline Hypotension prior to ICU & 151 & $64(42.4)$ & 267 & $75(28.1)$ & 0.003 \\
\hline Hypovolemia prior to ICU & 151 & $78(51.7)$ & 268 & $96(35.8)$ & 0.002 \\
\hline Radiocontrast dye prior to ICU & 153 & $44(28.8)$ & 268 & $52(19.4)$ & 0.03 \\
\hline Emergency admission & 153 & $148(96.7)$ & 270 & $267(98.9)$ & 0.12 \\
\hline Operative admission & 153 & $49(32.0)$ & 270 & 59 (21.9) & 0.02 \\
\hline Community acquired infection & 152 & $76(50.0)$ & 270 & $137(50.7)$ & 0.88 \\
\hline \multicolumn{6}{|l|}{ Source of infection } \\
\hline Pulmonary & 139 & $70(50.4)$ & 246 & $155(63.0)$ & 0.02 \\
\hline Abdominal & 139 & $45(32.4)$ & 246 & $52(21.1)$ & 0.02 \\
\hline Genitourinary & 139 & $14(10.1)$ & 246 & $12(4.9)$ & 0.05 \\
\hline Soft tissue & 139 & $14(10.1)$ & 246 & $28(12.4)$ & 0.7 \\
\hline SAPS $\|$ points & 153 & $43.0(35.0$ to 55.0$)$ & 270 & 38.0 (30.0 to 46.0$)$ & $<0.001$ \\
\hline SAPS II points without age and renal components & 153 & $24.0(18.0$ to 30.0$)$ & 270 & $24.0(17.0$ to 31.0$)$ & 0.7 \\
\hline SOFA D1 points & 153 & $9.0(7.0$ to 11.0$)$ & 270 & 7.0 (5.0 to 9.0$)$ & $<0.001$ \\
\hline SOFA D1 points, without renal points & 153 & $8.0(6.0$ to 10.0$)$ & 270 & $7.0(5.0$ to 9.0$)$ & 0.001 \\
\hline \multicolumn{6}{|l|}{ During ICU stay } \\
\hline Mechanical ventilation & 153 & $117(76.5)$ & 270 & $168(62.2)$ & 0.003 \\
\hline Use of sepsis corticosteroids & 151 & $55(36.4)$ & 264 & $46(17.4)$ & $<0.001$ \\
\hline Any vasoactive treatment & 153 & $134(87.6)$ & 270 & $181(67.0)$ & $<0.001$ \\
\hline Furosemide & 153 & $131(85.6)$ & 270 & $189(70.0)$ & $<0.001$ \\
\hline Dose of furosemide (iv) per ICU day, mg/day & 153 & $13.6(3.5-33.9)$ & 270 & $4.2(0.0-16.0)$ & $<0.001$ \\
\hline Aminoglycoside antibiotics & 153 & $1(0.7)$ & 270 & $6(2.2)$ & 0.22 \\
\hline Peptidoglycan antibiotics & 153 & $16(10.5)$ & 270 & $29(10.7)$ & 0.93 \\
\hline ACE inhibitor or ARB & 153 & $10(6.5)$ & 270 & $26(9.6)$ & 0.27 \\
\hline NSAID & 153 & $5(3.3)$ & 270 & $17(6.3)$ & 0.18 \\
\hline Radiocontrast dye & 153 & $15(9.8)$ & 270 & $33(12.2)$ & 0.45 \\
\hline \multicolumn{6}{|l|}{ Length of stay } \\
\hline ICU & 153 & 5.7 (3.3 to 10.3) & 270 & 3.8 (2.0 to 7.0$)$ & $<0.001$ \\
\hline Hospital & 153 & 16.0 (9.5 to 26.5$)$ & 270 & 15.0 (9.0 to 23.8$)$ & 034 \\
\hline 90-day mortality & 153 & $50(32.7)$ & 270 & $51(18.9)$ & 0.001 \\
\hline
\end{tabular}

Values are expressed as median (IQR) or count (percentage). Progression of acute kidney injury (AKI) is defined as onset of new AKI or worsening of AKI by at least one Kidney Disease: Improving Global Outcomes (KDIGO) stage within the first 5 days after ICU admission. COPD, chronic obstructive pulmonary disease; chronic kidney disease (CKD) was defined as structural or functional abnormalities of the kidney or glomerular filtration rate (GFR) $<60 \mathrm{ml} / \mathrm{minute} / 1.73 \mathrm{~m}{ }^{2}$ at least one week prior to ICU admission; hypotension, systolic blood pressure <90 mmHg for $1 \mathrm{~h}$; hypovolemia, by judgement of clinicians; SAPS II, simplified acute physiology score, SOFA D1, sequential organ failure assessment, first score during the ICU stay; iv, intravenous; ACE, angiotensin converting enzyme; ARB, angiotensin II receptor blocker; NSAID, non-steroidal anti-inflammatory drug. 
Table 2 Time-adjusted mean arterial pressure (MAP) and vasoactive treatments divided by progression of acute kidney injury

\begin{tabular}{|c|c|c|c|}
\hline & Progression of AKI & No progression of AKI & $P$-value \\
\hline & $\mathrm{N}=153$ & $\mathrm{~N}=\mathbf{2 7 0}$ & \\
\hline Time-adjusted MAP & 74.4 (68.3 to 80.8$)$ & 78.6 (72.9 to 85.4$)$ & $<0.001$ \\
\hline Time-adjusted MAP below $73 \mathrm{mmHg}(\%)$ & $69(45.1)$ & $68(25.2)$ & $<0.001$ \\
\hline Aggregate time below MAP thresholds, $\mathrm{m}$ & & & \\
\hline $55 \mathrm{mmHg}$ & $0.0(0.0$ to 10.0$)$ & $0.0(0.0$ to 10.0$)$ & 0.02 \\
\hline $60 \mathrm{mmHg}$ & $10.0(0.0$ to 70.0$)$ & $5.0(0.0$ to 30.0$)$ & 0.007 \\
\hline $65 \mathrm{mmHg}$ & $80.0(10.0$ to 280.0$)$ & $50.0(0.0$ to 160.0$)$ & 0.02 \\
\hline $70 \mathrm{mmHg}$ & $290.0(80.0$ to 620.0$)$ & 180.0 (40.0 to 480.0$)$ & 0.02 \\
\hline $75 \mathrm{mmHg}$ & $600.0(235.0$ to 985.0$)$ & $490.0(160.0$ to 870.0$)$ & 0.15 \\
\hline $80 \mathrm{mmHg}$ & 770.0 (445.0 to 1140.0$)$ & $750.0(287.5$ to 1102.5$)$ & 0.35 \\
\hline $85 \mathrm{mmHg}$ & 910.0 (660.0 to 1260.0$)$ & $1015.0(567.5$ to 1270.0$)$ & 0.86 \\
\hline Time adjusted aggregate time below MAP & & & \\
\hline $55 \mathrm{mmHg}$ & $0.0(0.0$ to 1.1$)$ & $0.0(0.0$ to 0.7$)$ & 0.01 \\
\hline $60 \mathrm{mmHg}$ & $1.1(0.0$ to 7.2$)$ & $0.4(0.0$ to 2.5$)$ & 0.002 \\
\hline $65 \mathrm{mmHg}$ & 7.7 (0.8 to 27.3$)$ & $3.6(0.0$ to 11.2$)$ & 0.002 \\
\hline $70 \mathrm{mmHg}$ & $25.4(7.0$ to 59.5$)$ & 14.8 (3.4 to 34.6$)$ & $<0.001$ \\
\hline $75 \mathrm{mmHg}$ & $56.9(23.0$ to 81.9$)$ & $37.3(12.2$ to 65.3$)$ & $<0.001$ \\
\hline $80 \mathrm{mmHg}$ & 76.3 (43.5 to 95.0$)$ & 56.5 (24.7 to 80.7$)$ & $<0.001$ \\
\hline $85 \mathrm{mmHg}$ & $93.1(65.5$ to 97.9$)$ & 75.8 (45.8 to 92.8$)$ & $<0.001$ \\
\hline Norepinephrine, $\mathrm{n}(\%)$ & $131(85.6)$ & $180(66.7)$ & $>0.001$ \\
\hline Max dose $\leq 24 \mathrm{~h}$ in $\mathrm{ICU}(\mu \mathrm{g} / \mathrm{kg} /$ minute) & 0.19 (0.07 to 0.42$)$ & 0.08 (0.00 to 0.19$)$ & $<0.001$ \\
\hline Max dose 1 to $5 \mathrm{~d}$ in ICU ( $\mu \mathrm{g} / \mathrm{kg} /$ minute) & 0.24 (0.11 to 0.50$)$ & 0.14 (0.08 to 0.30$)$ & $<0.001$ \\
\hline Epinephrine, $\mathrm{n}(\%)$ & $5(3.3)$ & $2(0.7)$ & 0.1 \\
\hline Max dose $\leq 24 \mathrm{~h}$ in ICU ( $\mathrm{hg} / \mathrm{kg} /$ minute) & 0.02 (0.02 to 0.02$)$ & 0.14 (0.02 to 0.66$)$ & 0.31 \\
\hline Max dose 1 to $5 \mathrm{~d}$ in ICU ( $\mathrm{\mu g} / \mathrm{kg} /$ minute) & 0.15 (0.02 to 0.15$)$ & 0.14 (0.06 to 0.78$)$ & 0.8 \\
\hline Dopamine, $\mathrm{n}(\%)$ & $2(1.3)$ & $2(0.7)$ & 0.62 \\
\hline Max dose $\leq 24 \mathrm{~h}$ in $\mathrm{ICU}(\mu \mathrm{g} / \mathrm{kg} /$ minute) & $5.0(2.7$ to 5.0$)$ & 9.1 (5.56 to 9.1) & 0.13 \\
\hline Max dose 1 to $5 \mathrm{~d}$ in ICU ( $\mathrm{\mu g} / \mathrm{kg} /$ minute) & $5.0(2.7$ to 5.0$)$ & 9.1 (5.56 to 9.1$)$ & 0.13 \\
\hline Vasopressor load max ( $\mu \mathrm{g} / \mathrm{kg} /$ minute) & & & \\
\hline$\leq 24 \mathrm{~h}$ in ICU & 0.32 (0.15 to 0.85$)$ & 0.14 (0.08 to 0.29$)$ & $<0.001$ \\
\hline 1 to $5 \mathrm{~d}$ in ICU & $0.40(0.22$ to 0.96$)$ & 0.15 (0.08 to 0.30$)$ & $<0.001$ \\
\hline Vasopressin, $n(\%)$ & $4(2.6)$ & $1(0.4)$ & 0.06 \\
\hline Dobutamine, $\mathrm{n}(\%)$ & $33(21.6)$ & $15(5.6)$ & $<0.001$ \\
\hline Levosimendan, $\mathrm{n}(\%)$ & $11(7.2)$ & $4(1.5)$ & $<0.002$ \\
\hline Milrinone, n (\%) & $4(2.6)$ & $1(0.4)$ & 0.06 \\
\hline
\end{tabular}

Values are expressed as count (percentage) or median (IQR). The median doses of drug doses are calculated for number of patients receiving aforementioned drug. $\mathrm{AKI}$, acute kidney injury; AUC, area under the curve; Vasopressor load max ( $\mu \mathrm{g} / \mathrm{kg} /$ minute) = norepinephrine max $(\mu \mathrm{g} / \mathrm{kg} / \mathrm{minute})+\mathrm{dopamine} \mathrm{max}(\mu \mathrm{g} / \mathrm{kg} / \mathrm{minute} / 2)+$ epinephrine $\max (\mu \mathrm{g} / \mathrm{kg} /$ minute).

First, to the first regression model the time-adjusted MAP was entered to describe MAP. The highest lactate value during the first $24 \mathrm{~h}, \mathrm{CKD}$, daily dose of intravenous furosemide, and time-adjusted MAP per mmHg (OR 0.96, 95\% CI 0.94 to 0.99) remained independent predictors of progression of AKI.
Second, instead of MAP as a continuous covariate, we tested time-adjusted MAP below the cutoff value of $73 \mathrm{mmHg}$ as a categorical variable. The highest lactate value during the first $24 \mathrm{~h}, \mathrm{CKD}$, daily dose of intravenous furosemide per $\mathrm{mg}$, use of dobutamine during the first $24 \mathrm{~h}$, and time-adjusted MAP below $73 \mathrm{mmHg}$ 


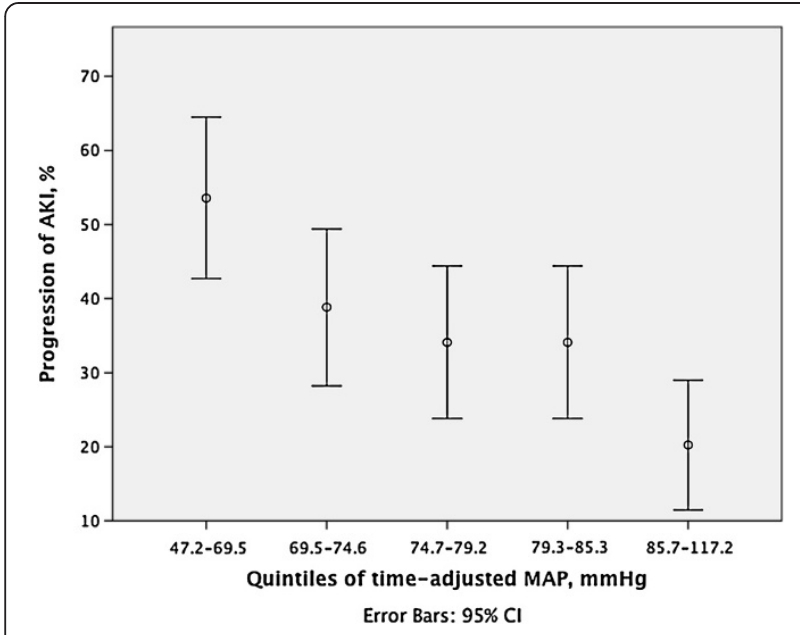

Figure 2 Progression of acute kidney injury (AKI) by quintiles of time-adjusted mean arterial pressure (MAP). The incidence of progression of AKI divided in quintiles of time-adjusted MAP presented for patients with severe sepsis during the first $24 \mathrm{~h}$ in the ICU.

(OR 2.57, 95\% CI 1.48 to 4.46 ) remained independent predictors of progression of AKI.

\section{Discussion}

In this large prospective multicenter observational study, progression of AKI occurred in 36\% of patients with severe sepsis. CKD, lactate level, dose of intravenous furosemide, use of dobutamine, and lower time-adjusted MAP or time-adjusted MAP below $73 \mathrm{mmHg}$ were independently associated with progression of AKI.

Few studies have assessed the relationship of hemodynamics and progression of AKI during early phases of

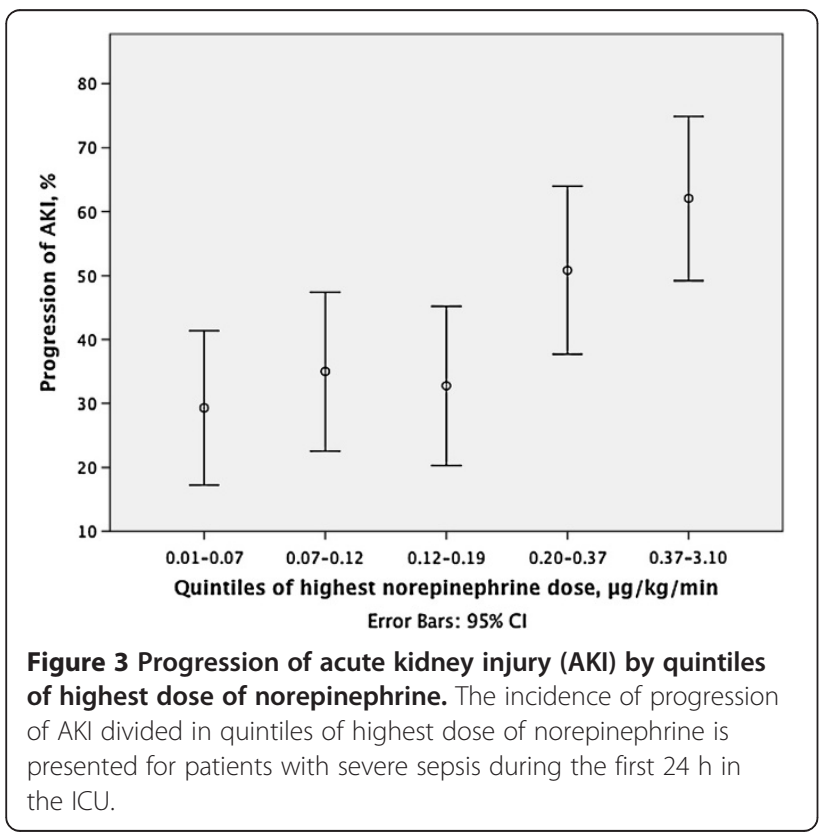

severe sepsis $[14,15]$. Maintaining mean arterial pressure over 60 to $65 \mathrm{mmHg}$ is currently suggested to maintain adequate renal blood flow and perfusion $[11,13]$. However, the true value of MAP that is beneficial for the kidney is unknown.

In the present study we found that patients with progression of AKI had significantly lower time-adjusted MAP (74 $\mathrm{mmHg}$ ), than those without progression $(79 \mathrm{mmHg}$ ). The best cutoff MAP level for prediction of AKI progression was $73 \mathrm{mmHg}$. Our finding is in line with recent studies, which have demonstrated that higher MAP levels than previously recommended may be required to maintain adequate renal perfusion [14,15]. An experimental study showed similar results in septic pigs [26]. In the subgroup analysis of 127 patients with septic shock Badin et al. found that patients who developed AKI had significantly lower time-averaged MAP than those who did not. The authors concluded that MAP between 72 and 82 $\mathrm{mm} \mathrm{Hg}$ could be necessary to prevent AKI in patients with septic shock [14]. In another recent retrospective cohort study of 274 septic patients, blood pressure was associated with need for RRT, maximal creatinine concentrations, and urine output. MAP under $75 \mathrm{mmHg}$ predicted the need for RRT. Consequently, the authors suggested that for renal protection, a MAP level of at least $75 \mathrm{mmHg}$ may be beneficial [15].

There is evidence that lower MAP is associated with worse outcome in patients with septic shock with AKI $[15,27]$. Recently, a small study of cardiac surgery patients showed that renal oxygen delivery and GFR improved when MAP was restored from $60 \mathrm{mmHg}$ to $75 \mathrm{mmHg}$ [28]. Current literature suggests that inflammatory processes and changes in renal microcirculation, with subsequent uncoupling of systemic and renal blood flow, may be central processes in the pathophysiology of AKI $[5,8,11]$. Renal autoregulation is disturbed during critical illness and its dependence on cardiac output is increased [12]. Thus, maintaining adequate renal perfusion to overcome derangements caused by loss of autoregulation may be one of the few current therapeutic options for prevention and treatment of AKI.

In the present study, when patients were divided by level of time-adjusted MAP into quintiles, the highest dose of norepinephrine was independently associated with progression of AKI in patients in the lowest quintile of time-adjusted MAP (47.2 to $69.5 \mathrm{mmHg}$ ). Our data showed that in the lowest quintile, the incidence of AKI progression increased with increasing doses of norepinephrine. These results may suggest that progression of AKI is more likely when higher doses of norepinephrine are required to maintain targeted blood pressure levels in more severely ill patients with severe sepsis, plausibly by causing excess constriction of regional vascular beds [29]. It may also reflect the impact of more severe illness 
Table 3 Univariable and multivariable regression analyses for factors associated with progression of AKI in patients with severe sepsis

\begin{tabular}{|c|c|c|c|c|c|c|}
\hline & \multicolumn{2}{|l|}{ Univariable analysis } & \multicolumn{4}{|c|}{ Multivariable analysis } \\
\hline & \multirow[b]{2}{*}{$\begin{array}{l}\text { Odds ratio } \\
(95 \% \mathrm{Cl})\end{array}$} & \multirow[b]{2}{*}{$P$-value } & \multicolumn{2}{|l|}{ Model 1} & \multicolumn{2}{|l|}{ Model 2} \\
\hline & & & $\begin{array}{l}\text { Odds ratio } \\
(95 \% \mathrm{Cl})\end{array}$ & $P$-value & $\begin{array}{l}\text { Odds ratio } \\
(95 \% \mathrm{Cl})\end{array}$ & $P$-value \\
\hline CKD & $4.696(1.901,11.600)$ & 0.001 & $6.72(2.19,20.63)$ & 0.001 & $7.24(2.36,22.23)$ & 0.001 \\
\hline Diabetes mellitus & $1.665(1.041,2.662)$ & 0.033 & NS & & NS & \\
\hline Hypotension prior to ICU & $1.883(1.239,2.863)$ & 0.003 & NS & & NS & \\
\hline Radiocontrast dye prior to ICU & $1.677(1.056,2.664)$ & 0.029 & NS & & NS & \\
\hline Operative admission & $1.685(1.079,2.631)$ & 0.022 & NS & & NS & \\
\hline Abdominal infection & $1.786(1.117,2.855)$ & 0.015 & NS & & NS & \\
\hline SOFA D1 without renal point & $1.136(1.056,1.223)$ & 0.001 & NS & & NS & \\
\hline Use of sepsis corticosteroids & $2.715(1.715,4.298)$ & $<0.001$ & NS & & NS & \\
\hline $\begin{array}{l}\text { Use of dobutamine within first } 24 \mathrm{~h} \\
\text { in the ICU }\end{array}$ & $4.607(2.259,9.395)$ & $<0.001$ & $2.42(1.00,5.81)$ & 0.049 & $2.68(1.11,6.48)$ & 0.028 \\
\hline Norepinephrine max dose $24 \mathrm{~h}$ & $4.234(2.036,8.803)$ & $<0.001$ & NS & & NS & \\
\hline Daily dose of furosemide (iv, mg) & $1.006(1.002,1.009)$ & 0.001 & $1.00(1.00,1.01)$ & 0.002 & $1.01(1.00,1.01)$ & 0.001 \\
\hline Fluid balance per hour on D1 in ICU & $1.002(1.000,1.003)$ & 0.005 & NS & & NS & \\
\hline Lactate $24 \mathrm{~h}$ highest & $1.374(1.218,1.549)$ & $<0.001$ & $1.36(1.18,1.57)$ & $<0.001$ & $1.35(1.17,1.55)$ & $<0.001$ \\
\hline Time-adjusted MAP & $0.952(0.931,0.973)$ & $<0.001$ & $0.96(0.94,0.99)$ & 0.006 & - & \\
\hline Time-adjusted MAP below $73 \mathrm{mmHg}$ & $2.440(1.602,3.716)$ & $<0.001$ & - & & $2.57(1.48,4.46)$ & 0.001 \\
\hline
\end{tabular}

CKD, chronic kidney disease defined as structural or functional abnormalities of the kidney or glomerular filtration rate (GFR) $<60 \mathrm{ml} / \mathrm{miute} / 1.73 \mathrm{~m}{ }^{2}$ at least one week prior to ICU admission; hypotension, systolic blood pressure $<90 \mathrm{mmHg}$ for $1 \mathrm{~h}$; SOFA D1, sequential organ failure assessment, first score during the ICU stay; iv, intravenous; MAP, mean arterial pressure; NS, not significant.

and more profound vascular hyporesponsiveness on the progression of AKI [30].

Norepinephrine is the vasopressor of choice recommended for restoration of MAP in acute circulatory failure during sepsis [21]. Even though norepinephrine may have deleterious effects on renal blood flow and renal function in healthy subjects [31,32], it may increase renal perfusion and GFR in patients with circulatory failure $[28,33]$. However, in an experimental study norepinephrine failed to increase renal microcirculation in septic pigs, in spite of improved perfusion pressure [34]. There is also evidence of the association of adverse outcome in septic shock with increasing vasopressor load [23]. As renal blood flow and perfusion may show individual variation, the evaluation of renal blood flow, and its distribution and resistive index has been proposed for finding the optimal MAP target for each patient $[33,35]$. With better knowledge of the individual optimal MAP excessive use of vasopressors may be avoided.

Higher blood lactate, lower $\mathrm{pH}$ and lower $\mathrm{BE}$ were associated with progression of AKI indicating, that systemic hypoperfusion was present, even though cardiac function was not included in this study. Hence, the use of inotropes may be explained by attempts to increase insufficient cardiac output in patients with progression of
AKI. However, low BE and $\mathrm{pH}$ may also be consequences of AKI. Recent data indicate that dobutamine may not improve microcirculatory perfusion in septic shock despite an increase in cardiac index [36]. In addition, some inotropes may have independent deleterious effects on the septic kidney [37]. In agreement with prospective randomized studies $[38,39]$ indicating that the use of colloids in the ICU cause AKI, we also found an association between colloids and progression of AKI.

This study has some limitations. First, although patient data were collected prospectively, patients were not randomized to treatment arms targeting different MAP values or vasopressors, inotropes or fluid treatment. Thus, the association of time-adjusted MAP, and time-adjusted MAP deficits below threshold values, as well as higher vasopressor and fluid load to progression of AKI may partly be explained by the impact of more severe illness. Second, exclusion of patients who died during the first five days may have caused selection bias by elimination of the most severely ill patients (Additional file 1). However, inclusion of patients who died would also cause bias. Progression of $\mathrm{AKI}$ and death may be considered as competing risk, as patients may die before progression of AKI is identified. Nevertheless, some patients could have died without progression of AKI. Third, this study focused on MAP rather than mean perfusion pressure of the kidney, as 
intra-abdominal pressure (IAP) was measured only in a few patients, and information on IAP levels in the majority of patients was lacking. Fourth, data on cardiac function or mixed venous oxygen saturation were collected in only a minority of patients monitored with a pulmonary artery catheter. Therefore, the associations between low cardiac output or low mixed venous oxygen saturation during the early phase of severe sepsis and progression of AKI could not be assessed in this study. Finally, during the FINNAKI study we only collected data on the type of colloids received during $48 \mathrm{~h}$ prior to ICU admission. Therefore, we could not assess the association of the use of colloids, nor on the use of different colloids, particular HES, with progression of AKI.

\section{Conclusions}

In this large prospective study of patients with severe sepsis, we found that time-adjusted MAP was significantly lower and independently associated with progression of AKI in these patients. Our findings suggest that avoiding hypotensive episodes (MAP under $73 \mathrm{mmHg}$ ) may prevent progression of AKI. This hypothesis should be confirmed in a prospective randomized trial.

\section{Key messages}

- Time-adjusted MAP under $73 \mathrm{mmHg}$ was associated with progression of AKI in critically ill patients with severe sepsis

- The highest dose of norepinephrine was not associated with progression of AKI except in patients in the lowest quintile (47.2 to $69.5 \mathrm{mmHg}$ ) of time-adjusted MAP

\section{Additional files}

Additional file 1: Table S1. Characteristics of patients who died within the first 5 days in the ICU.

Additional file 2: Figure S1. A, B, and C. Examples of registered mean arterial pressures (MAP) and MAP area under curve (AUC) during the first $24 \mathrm{~h}$ in the ICU.

Additional file 3: Figure S2. Onset and progression of acute kidney injury (AKI) from the first stage of AKI to the highest stage of AKI during the first 5 days in the ICU.

Additional file 4: Figure S3. Time-adjusted mean arterial pressure stratified by progression of acute kidney injury (AKI)

Additional file 5: Table S2. Area under curve of mean arterial pressure (MAP AUC) under threshold values and time-adjusted MAP deficit below MAP thresholds divided by progression of acute kidney injury (AKI).

Additional file 6: Table S3. Acid-base balance and plasma lactate values between patients with or without progression of acute kidney injury (AKI).

\section{Abbreviations}

ACCP/SCCM: American College of Chest Physicians/Society of Critical Care Medicine; AKI: Acute kidney injury; AUC: Area under curve; BE: Base excess; CKD: Chronic kidney disease; CRF: Case report form; DIC: Disseminated intravascular coagulation; GFR: Glomerular filtration rate; HES: Hydroxyethyl starches; IAP: Intra abdominal pressure; ICD-10: International Classification of Diseases; KDIGO: Kidney disease: improving global outcomes; MAP: Mean arterial pressure; MDRD: Modification of diet in renal disease; OR: Odds ratio; ROC: Receiver operating characteristic; RRT: Renal replacement therapy; SAPS II: Simplified acute physiology score; SCr: Serum creatinine; SOFA: Sequential organ failure assessment.

\section{Competing interests}

The authors declare to have no competing interests.

\section{Authors' contributions}

MP and EW performed the data analysis and drafted the manuscript (equal contribution). STV and VP participated in designing the study and critically revised the manuscript. AMK, AU, KMK, SH, OI, RLS, RH, AK and SK critically revised the manuscript. All authors participated in the data collection and read and approved the final manuscript.

\section{Acknowledgements}

We thank Tieto Healthcare and Welfare Ltd for database management. We received Clinical Research funding (EVO) from Helsinki University Hospital and from Lapland Central Hospital. We have received grants from the Academy of Finland, the Juselius Foundation and the Finnish Society of Intensive Care. MP has received a grant from the Finnish Cultural Foundation. EW has received grants from the Åland Island Cultural Foundation (Ålands kulturstiftelse) and the Medical Society of Finland (Finska läkaresällskapet).

The FINNAKI study group is acknowledged for their invaluable work in planning and conducting the study. FINNAKI study group: Central Finland Central Hospital: Raili Laru-Sompa, Anni Pulkkinen, Minna Saarelainen, Mikko Reilama, Sinikka Tolmunen, Ulla Rantalainen, Marja Miettinen. Helsinki University Central Hospital: Ville Pettilä, Kirsi-Maija Kaukonen, Anna-Maija Korhonen, Sara Nisula, Suvi Vaara, Raili Suojaranta-Ylinen, Leena Mildh, Mikko Haapio, Laura Nurminen, Sari Sutinen, Leena Pettilä, Helinä Laitinen, Heidi Syrjä, Kirsi Henttonen, Elina Lappi, Hillevi Boman. Jorvi Central Hospital: Tero Varpula, Päivi Porkka, Mirka Sivula Mira Rahkonen, Anne Tsurkka, Taina Nieminen, Niina Prittinen. Kuopio University Hospital: Ilkka Parviainen, Ari Uusaro, Esko Ruokonen, Stepani Bendel, Niina Rissanen, Maarit Lång, Sari Rahikainen, Saija Rissanen, Merja Ahonen, Elina Halonen, Eija Vaskelainen. Lapland Central Hospital: Meri Poukkanen, Esa Lintula, Sirpa Suominen. Länsi Pohja Central Hospital: Jorma Heikkinen, Timo Lavander, Kirsi Heinonen, Anne-Mari Juopperi. Middle Ostrobothnia Central Hospital: Tadeusz Kaminski, Fiia Gäddnäs, Tuija Kuusela, Jane Roiko. Satakunta Hospital District: Vesa Lund, Päivi Tuominen, Pauliina Perkola, Riikka Tuominen, Marika Hietaranta, Satu Johansson. South Karelia Central Hospital: Seppo Hovilehto, Anne Kirsi, Pekka Tiainen, Tuija Myllärinen, Pirjo Leino, Anne Toropainen. Tampere University Hospital: Anne Kuitunen, Ilona Leppänen, Markus Levoranta, Sanna Hoppu, Jukka Sauranen, Jyrki Tenhunen, Atte Kukkurainen, Samuli Kortelainen, Simo Varila. Turku University Hospital: Outi Inkinen, Niina Koivuviita, Jutta Kotamäki, Anu Laine. Oulu University Hospital: Tero Ala-Kokko, Jouko Laurila, Sinikka Sälkiö. Vaasa Central Hospital: Simo-Pekka Koivisto, Raku Hautamäki, Maria Skinnar.

\section{Author details}

${ }^{1}$ Department of Anaesthesia and Intensive Care, Lapland Central Hospital, Rovaniemi, Finland. ${ }^{2}$ Intensive Care Unit, Division of Anaesthesia and Intensive Care Medicine, Department of Surgery, Helsinki, Finland. ${ }^{3}$ Department of Clinical Sciences, University of Helsinki, Helsinki, Finland. ${ }^{4}$ ANZIC-RC, Department of Epidemiology and Preventive Medicine, Monash University, Melbourne, Australia. ${ }^{5}$ Intensive Care Unit, Kuopio University Hospital, Kuopio, Finland. ${ }^{6}$ Department of Anaesthesia and Intensive Care Medicine, South Karelia Central Hospital, Lappeenranta, Finland. ${ }^{7}$ Department of Anaesthesia and Intensive Care Medicine, Turku University Hospital, Turku, Finland. ${ }^{8}$ Department of Anaesthesia and Intensive Care Medicine, Central Finland Central Hospital, Jyväskylä, Finland. ${ }^{9}$ Department of Anaesthesia and Intensive Care Medicine, Vaasa Central Hospital, Vaasa, Finland. ${ }^{10}$ Department of Intensive Care Medicine, Tampere University Hospital, Tampere, Finland.

Received: 24 May 2013 Accepted: 14 November 2013

Published: 13 December 2013 


\section{References}

1. Oppert M, Engel C, Brunkhorst FM, Bogatsch H, Reinhart K, Frei U, Eckardt KU, Loeffler M, John S, German Competence Network Sepsis (Sepnet): Acute renal failure in patients with severe sepsis and septic shock-a significant independent risk factor for mortality: results from the German prevalence study. Nephrol Dial Transplant 2008, 23:904-909.

2. Thakar CV, Christianson A, Freyberg R, Almenoff P, Render ML: Incidence and outcomes of acute kidney injury in intensive care units: a Veterans Administration study. Crit Care Med 2009, 37:2552-2558.

3. Mandelbaum T, Scott DJ, Lee J, Mark RG, Malhotra A, Waikar SS, Howell MD, Talmor D: Outcome of critically ill patients with acute kidney injury using the acute kidney injury network criteria. Crit Care Med 2011, 39:2659-2664.

4. Bagshaw SM, Lapinsky S, Dial S, Arabi Y, Dodek P, Wood G, Ellis P, Guzman J, Marshall J, Parrillo JE, Skrobik Y, Kumar A, Cooperative Antimicrobial Therapy of Septic Shock (CATSS) Database Research Group: Acute kidney injury in septic shock: clinical outcomes and impact of duration of hypotension prior to initiation of antimicrobial therapy. Intensive Care Med 2009, 35:871-881.

5. Wan L, Bagshaw SM, Langenberg C, Saotome T, May C, Bellomo R Pathophysiology of septic acute kidney injury: what do we really know? Crit Care Med 2008, 36:S198-S203.

6. Bagshaw SM, George C, Bellomo R, ANZICS Database Management C: Early acute kidney injury and sepsis: a multicentre evaluation. Crit Care 2008, 12:R47.

7. Uchino S, Kellum JA, Bellomo R, Doig GS, Morimatsu H, Morgera S, Schetz M, Tan I, Bouman C, Macedo E, Gibney N, Tolwani A, Ronco C, Beginning and Ending Supportive Therapy for the Kidney (BEST Kidney) Investigators: Acute renal failure in critically ill patients: a multinational, multicenter study. JAMA 2005, 294:813-818

8. Zarjou A, Agarwal A: Sepsis and acute kidney injury. J Am Soc Nephrol 2011, 22:999-1006.

9. Schrier RW, Wang W: Acute renal failure and sepsis. N Engl J Med 2004, 351:159-169.

10. Lerolle N, Nochy D, Guerot E, Bruneval P, Fagon JY, Diehl JL, Hill G: Histopathology of septic shock induced acute kidney injury: apoptosis and leukocytic infiltration. Intensive Care Med 2010, 36:471-478.

11. Prowle J, Bagshaw SM, Bellomo R: Renal blood flow, fractional excretion of sodium and acute kidney injury: time for a new paradigm? Curr Opin Crit Care 2012, 18:585-592.

12. Prowle JR, Molan MP, Hornsey E, Bellomo R: Measurement of renal blood flow by phase-contrast magnetic resonance imaging during septic acute kidney injury: a pilot investigation. Crit Care Med 2012, 40:1768-1776.

13. Joannidis M, Druml W, Forni LG, Groeneveld AB, Honore P, Oudemans-van Straaten HM, Ronco C, Schetz MR, Woittiez AJ, Critical Care Nephrology Working Group of the European Society of Intensive Care Medicine: Prevention of acute kidney injury and protection of renal function in the intensive care unit. Expert opinion of the working group for Nephrology, ESICM. Intensive Care Med 2010, 36:392-411.

14. Badin J, Boulain T, Ehrmann S, Skarzynski M, Bretagnol A, Buret J, Benzekri-Lefevre D, Mercier E, Runge I, Garot D, Mathonnet A, Dequin PF, Perrotin D: Relation between mean arterial pressure and renal function in the early phase of shock: a prospective, explorative cohort study. Crit Care 2011, 15:R135.

15. Dunser MW, Takala J, Ulmer H, Mayr VD, Luckner G, Jochberger S, Daudel F, Lepper P, Hasibeder WR, Jakob SM: Arterial blood pressure during early sepsis and outcome. Intensive Care Med 2009, 35:1225-1233.

16. Nisula S, Kaukonen KM, Vaara ST, Korhonen AM, Poukkanen M, Karlsson S, Haapio M, Inkinen O, Parviainen I, Suojaranta-Ylinen R, Laurila JJ, Tenhunen J, Reinikainen M, Ala-Kokko T, Ruokonen E, Kuitunen A, Pettila V, FINNAKI Study G: Incidence, risk factors and 90-day mortality of patients with acute kidney injury in Finnish intensive care units: the FINNAKI study. Intensive Care Med 2013, 39:420-428

17. Bone RC, Balk RA, Cerra FB, Dellinger RP, Fein AM, Knaus WA, Schein RM, Sibbald WJ: Definitions for sepsis and organ failure and guidelines for the use of innovative therapies in sepsis. The ACCP/SCCM Consensus Conference Committee. American College of Chest Physicians/Society of Critical Care Medicine. Chest 1992, 101:1644-1655.

18. Anonymous Kidney Disease: Improving Global Outcomes (KDIGO) Acute Kidney Injury Work Group. KDIGO clinical practice guideline for acute kidney injury. Kidney Inter Suppl 2012, 2:1-138.
19. Levey AS, Coresh J, Balk E, Kausz AT, Levin A, Steffes MW, Hogg RJ, Perrone RD, Lau J, Eknoyan G, National Kidney Foundation: National Kidney Foundation practice guidelines for chronic kidney disease: evaluation, classification, and stratification. Ann Intern Med 2003, 139:137-147.

20. National Kidney F: K/DOQI clinical practice guidelines for chronic kidney disease: evaluation, classification, and stratification. Am J Kidney Dis 2002 39:S1-S266

21. Dellinger RP, Levy MM, Carlet JM, Bion J, Parker MM, Jaeschke R, Reinhart $K$, Angus DC, Brun-Buisson C, Beale R, Calandra T, Dhainaut JF, Gerlach H, Harvey M, Marini JJ, Marshall J, Ranieri M, Ramsay G, Sevransky J, Thompson BT, Townsend S, Vender JS, Zimmerman JL, Vincent JL: Surviving Sepsis Campaign: international guidelines for management of severe sepsis and septic shock: 2008. Intensive Care Med 2008, 34:17-60.

22. Russell JA, Walley KR, Singer J, Gordon AC, Hébert PC, Cooper DJ, Holmes CL, Mehta S, Granton JT, Storms MM, Cook DJ, Presneill JJ, Ayers D, VASST Investigators: Vasopressin versus norepinephrine infusion in patients with septic shock. N Engl J Med 2008, 358:877-887.

23. Dunser MW, Ruokonen E, Pettila V, Ulmer H, Torgersen C, Schmittinger CA, Jakob S, Takala J: Association of arterial blood pressure and vasopressor load with septic shock mortality: a post hoc analysis of a multicenter trial. Crit Care 2009, 13:R181.

24. Gillies M, Bellomo R, Doolan L, Buxton B: Bench-to-bedside review: Inotropic drug therapy after adult cardiac surgery - a systematic literature review. Crit Care 2005, 9:266-279.

25. Ray P, Le Manach Y, Riou B, Houle TT: Statistical evaluation of a biomarker. Anesthesiology 2010, 112:1023-1040

26. Correa TD, Vuda M, Takala J, Djafarzadeh S, Silva E, Jakob SM: Increasing mean arterial blood pressure in sepsis: effects on fluid balance, vasopressor load and renal function. Crit Care 2013, 17:R21.

27. Varpula M, Tallgren M, Saukkonen K, Voipio-Pulkki LM, Pettila V: Hemodynamic variables related to outcome in septic shock. Intensive Care Med 2005, 31:1066-1071.

28. Redfors B, Bragadottir G, Sellgren J, Sward K, Ricksten SE: Effects of norepinephrine on renal perfusion, filtration and oxygenation in vasodilatory shock and acute kidney injury. Intensive Care Med 2011, 37:60-67.

29. Bellomo R, Giantomasso DD: Noradrenaline and the kidney: friends or foes? Crit Care 2001, 5:294-298

30. Levy B, Collin S, Sennoun N, Ducrocq N, Kimmoun A, Asfar P, Perez P, Meziani F: Vascular hyporesponsiveness to vasopressors in septic shock: from bench to bedside. Intensive Care Med 2010, 36:2019-2029.

31. Hoogenberg K, Smit AJ, Girbes AR: Effects of low-dose dopamine on renal and systemic hemodynamics during incremental norepinephrine infusion in healthy volunteers. Crit Care Med 1998, 26:260-265.

32. Richer M, Robert $\mathrm{S}$, Lebel $\mathrm{M}$ : Renal hemodynamics during norepinephrine and low-dose dopamine infusions in man. Crit Care Med 1996, 24:1150-1156.

33. Deruddre S, Cheisson G, Mazoit JX, Vicaut E, Benhamou D, Duranteau J: Renal arterial resistance in septic shock: effects of increasing mean arterial pressure with norepinephrine on the renal resistive index assessed with Doppler ultrasonography. Intensive Care Med 2007, 33:1557-1562

34. Krejci V, Hiltebrand LB, Sigurdsson GH: Effects of epinephrine, norepinephrine, and phenylephrine on microcirculatory blood flow in the gastrointestinal tract in sepsis. Crit Care Med 2006, 34:1456-1463.

35. Benes J, Chvojka J, Sykora R, Radej J, Krouzecky A, Novak I, Matejovic M: Searching for mechanisms that matter in early septic acute kidney injury: an experimental study. Crit Care 2011, 15:R256.

36. Hernandez G, Bruhn A, Luengo C, Regueira T, Kattan E, Fuentealba A, Florez J, Castro R, Aquevedo A, Pairumani R, McNab P, Ince C: Effects of dobutamine on systemic, regional and microcirculatory perfusion parameters in septic shock: a randomized, placebo-controlled, double-blind, crossover study. Intensive Care Med 2013, 39:1435-1443.

37. Heringlake M, Wernerus $M$, Grunefeld J, Klaus S, Heinze H, Bechtel M, Bahlmann L, Poeling J, Schon J: The metabolic and renal effects of adrenaline and milrinone in patients with myocardial dysfunction after coronary artery bypass grafting. Crit Care 2007, 11:R51.

38. Perner A, Haase N, Guttormsen AB, Tenhunen J, Klemenzson G, Åneman A, Madsen KR, Møller MH, Elkjær JM, Poulsen LM, Bendtsen A, Winding R, Steensen M, Berezowicz P, Søe-Jensen P, Bestle M, Strand K, Wiis J, White JO, Thornberg KJ, Quist L, Nielsen J, Andersen LH, Holst LB, Thormar K, Kjældgaard A, Fabritius ML, Mondrup F, Pott FC, Møller TP, et al: 
Hydroxyethyl starch 130/0.42 versus Ringer's acetate in severe sepsis. N Engl J Med 2012, 367:124-134.

39. Myburgh JA, Finfer S, Bellomo R, Billot L, Cass A, Gattas D, Glass P, Lipman J, Liu B, McArthur C, McGuinness S, Rajbhandari D, Taylor CB, Webb SA, CHEST

Australian and New Zealand Intensive Care Society Clinical Trials, Group:

Hydroxyethyl starch or saline for fluid resuscitation in intensive care. N Engl J Med 2012, 367:1901-1911.

doi:10.1186/cc13161

Cite this article as: Poukkanen et al: Hemodynamic variables and progression of acute kidney injury in critically ill patients with severe sepsis: data from the prospective observational FINNAKI study. Critical Care 2013 17:R295.

\section{Submit your next manuscript to BioMed Central and take full advantage of:}

- Convenient online submission

- Thorough peer review

- No space constraints or color figure charges

- Immediate publication on acceptance

- Inclusion in PubMed, CAS, Scopus and Google Scholar

- Research which is freely available for redistribution 